\title{
Understanding cities through the process of urbanization
}

\author{
S. Singh \\ Centre for Political Studies, School of Social Sciences, \\ Jawaharlal Nehru University, India
}

\begin{abstract}
This paper aims to gain an understanding of the processes of urbanization and the transformations taking place within cities. It looks at city restructuring through the study of Gated Communities. Gated Communities have been mushrooming all over the world, significantly impacting the lives of the people and the cities at large. In this paper, the author attempts to engage with the urban practice of the gating of communities, both at the theoretical and the empirical level. The empirical study was carried out in the DLF Phase V area of Gurgaon, India. This area has seen the development of numerous Gated Compounds over the past decade and it is this sudden urban transformation that the author wishes to engage and understand.

Keywords: urbanization, Gated Communities, securitization, subjectivities, exclusion, Gurgaon.
\end{abstract}

\section{Introduction}

Scholars have argued that, for a very long time, cities have not received any attention in the academia. For some it has been nothing more than an object that needed to be moulded by its ruling class and ruling authorities to impose order and discipline on its subjects. Some scholars who have closely engaged with the literature on urbanization and cities have argued that it was the need to regulate the behaviour of citizens and to preserve the status quo that led to the engagement with urban studies. Khosla [1] has argued that it is only in the last century that the city has begun to be regarded by planners as an organism with its own and unpredictable dynamism and where the pursuit of an ideal master plan has become a dated notion. However, on the other hand, there is a sizeable group of people for whom the city remains, of which Nair [2] calls merely the 'Other' 
of a real or imagined rural India, either in terms of the ways it corrupts or dehumanizes the city dwellers, or a place where individualism would flourish and generate new civic virtues. This variation on how the city is looked at and the uneven reconstruction of the city is what ignites my interest. It is through these kinds of uneven transformations that take place in the cities that the irreversible link between urbanization and capitalism comes to the forefront. The capitalist intentions are reinforced through these urbanization processes taking place in the cities.

\section{Role of capital in the neoliberal restructuring of the city}

Harvey [3] argues that the city is an agglomeration of productive forces built by labour employed within a temporal process of circulation of capital. He argues that the city is nourished out of the metabolism of capitalist production for exchange on the world market and is supported out of a highly sophisticated system of production and distribution organized within its confines [3]. He points out that the role of capital in urban processes can be understood by understanding the phases through which capital accumulation goes through. The first circuit concerns the production of commodities within manufacturing giving way to overproduction of goods. Capital thus moves to the second circuit where it gets invested in fixed capital such as infrastructure, housing, construction of offices leading to the growth of town and city. The state plays a crucial role in mediating the flows of capital from primary to secondary circuit through the creation of financial tools. The tertiary circuit involves investment in scientific knowledge and technological advancement to reproduce labour power [4]. Thus, we see that the process of urbanization and capitalism are conjoined.

The relation between capitalism and urbanization has also been pointed out by Lefebvre. He argues that capitalism has survived into the $20^{\text {th }}$ century through the production of space and that it has been an increasingly urbanized space that has been produced. Secondly, he points out that the increasing urbanization makes the urban the primary level at which individuals now experience, live out, and react to the totality of social transformations and structures in the world around them. Thus, Lefebvre [5] argues that to dissect the urban process in all its fullness is to lay bare the roots of consciousness formation in the material realities of daily life, which again points to the irreversible link between urbanization and capitalism.

Thus, it becomes evident that urbanization is not divorced from capitalist expansion. The latest manifestation of capitalism in the form of neoliberalization has affected urbanization in its own new ways. What is most troubling and surprising about the process of urbanization guided by neoliberal principles, is the similarity across borders irrespective of the social, economic and political disparities. As has also been pointed out by Harvey that, "what is remarkable is not that urbanism is so different but that it is so similar in all metropolitan centres of the world in spite of significant differences in social policy, cultural tradition, administrative and political arrangements, institutions and laws, and so on" [3]. And it is precisely for this reason that it becomes imperative to 
understand such developments at a much deeper level. Let us now look at Gated Communities as spaces created by the process of urbanization guided by the motives of capitalist accumulation which in turn creates new subjects and new forms of subjectivities.

\section{Gated communities as markers of neoliberal city-life}

Gated communities, which are commonly referred to as being militarized, securitized, exclusive and excluding, antisocial, segregating, manufactured, inauthentic have become one of the exemplars of contemporary urbanism and the neoliberal city [7] - a city that is typically characterized by the declining significance of public housing and public spaces, rise of entrepreneurial privatized landscapes of gentrification, downtown redevelopment, mega projects and other forms of uneven development. This uneven process of urban development has been the reason why people have had different meanings, connotations and understanding of what the city is.

Scholars like Hirt and Petrovic [8], working on gated enclaves have defined it as a 'residential area that is enclosed by walls, fences, or landscaping that provides a physical barrier to entry'; it includes 'streets and neighbourhood amenities', is initiated by a development firm and governed privately by a homeowner association, thus, becoming a global commodity and cultural icon [8]. According to Caldeira, Gated communities or "fortified enclaves" are privatized, enclosed, and monitored spaces for residence, consumption, leisure, and work.

Blakely and Snyder [9] describe gated communities as residential areas with restricted access and in which public space is privatized. In most of the literature, gated communities are regarded as the results of global neo-liberal restructuring leading to class polarization and concerns about safety and security. Scholars have argued that the search for a lifestyle goes together with the search for a community, which is achieved through the homogeneity of residents in terms of class and cultural background. The close link between culture and urban development in the form of Gated Communities has led many scholars like Tanulku [10] to describe gated communities as "cultural enclaves".

In Behind the Gates: Life, Security, and the Pursuit of Happiness in Fortress America, Low [11] expresses her disdain for the gated, architecturally uniform, covenant-controlled residential development using the vilest epithet she can muster: "nice." This process of urbanization aiming towards a level of cultural homogenization through the pursuit of 'niceness', the process of maintaining a clean, orderly, homogeneous, and controlled neighbourhood to preserve stable housing values, is also a way of creating "whiteness". Whiteness, as argued by Epperson, has less to do with racial identity than a mindless, submissive cultural assimilation [12].

Where on the one hand there is assimilation, on the other hand, the development of these new gated communities and fenced cities has come with the deepening fragmentation of the social space of the city. Scholars have argued that such communities, in their different modalities, try to fit into the city like 
independent units, with filtered access, based on the labour necessities and of services in general, with the city "more outside" of their boundaries [13]. There is constant isolation that keeps taking place because certain sections of the population gain access while the others are denied access. The most compelling message running throughout the varied international case studies is how gated communities have acted as mechanisms to mediate growing inequalities [7]. It is seen as the latest manifestation of social segregation - the newest method developed by the "affluent and upper middle-class groups" to locate themselves "in the best city areas". Thus, instead of looking at gated communities as a sign of urban development, it should rather be seen as a sign of relapse and regression or what Helsley and Strange [14] call something of an atavism. As we all are well aware that the first permanent structures that humans built were fortifications. Ancient walled towns were designed to protect life and property by keeping the barbarians out [14]. Gated Communities are a modified version of such structures that have been built in the past.

Fear of crime and a desire for development that is secure has been the motivating force behind the development of Gated Communities. Strict human security and CCTVs are prominent in most of the Gated Communities in addition to the high wall construction. Even those who are developing and marketing gated communities have strictly identified specific functions for the gates. Primarily, they pointed out that the fear of crime and the desire for peace of mind were the main reasons that have accelerated the construction of Gated Communities. They employed the gates to limit access, ensure privacy, and reduce traffic.

Gates were seen as providing a sense of security, if not the real thing. Along with security it provided prestige and became a marker of one's status and quality of living. Atkinson et al. [15] point out that the adherence to the principle of Secured by Design for individual properties, in addition to consideration of the security attributes of communal areas and external boundaries, is a characteristic of gated developments which appears to bring the benefits of actual and perceived security to residents [15]. In gated projects, marketers create places where buyers can live with 'people they are comfortable with'. It is so thus, that Low argues that the gates establish a 'refuge from diversity' [16].

Few thinkers differentiate between the actual crime rate and the residents' perceptions of safety, referred to as fear of crime. Although actual crime rates have been decreasing in recent history, fear of crime is increasing. Fear of crime has been noted to be more widespread than actual crime [17]. Fear of crime negatively affects quality of life over a long period of time, leading people to unnecessarily secure themselves, remove themselves from social activities, and increase levels of distrust of others [17]. This fear of crime which is generated and not something that existed is what ultimately leads to the creation of neoliberal subject. The fear of crime created by the neoliberal forces aims as producing legitimate consent and willingness for the products that they are or would be creating which is packaged as a need and necessity for a safe and good life of the people and sold in the market. 
Through these urban developments, one is made to believe that public space engenders fears. As Don Mitchell [18] has argued that these fears are derived from the sense of public space as an uncontrolled space, as a space in which civilization is exceptionally fragile. Thus, according to the neoliberal logic there is need for the appropriation of public spaces as controlled and planned spaces which in turn would be the marker of higher civilization.

Though Gated Communities may be a defended space but they leave the street they front vulnerable. Gooblar has very rightly argued that gated communities may improve the security of inhabitants but at the cost of their greater neighbourhood's safety [19]. They have potential impacts on their surrounding neighbourhoods such as threatening safety, restricting access, and perpetuating social inequality. They physically restrain access to a space that is otherwise a public or community space, by privatizing them. Some gated communities even privatize civic services such as police protection, fire station and education. As Gooblar has argued that Gated Communities offer higher and stricter levels of control over living spaces and property as a response to the fear of what can happen to property and people [19], however, one fails to understand that this process of controlling and regulating lives of people is a mode of creating disciplined citizens. Also, what one misses to analyse is that fact that this so called safety and security that is being provided comes with a cost. Let us now try to engage with the development of Gated Communities in Gurgaon.

\section{Gurgaon: a case study of Gated Communities}

After briefly engaging with the various causes and consequences of gating, in this section I will be discussing about the process of gating in the Indian context. I would be specifically looking at the city of Gurgaon in Haryana, which is a part of the National Capital Region in India. The map of urban development in Gurgaon is so skewed that the city gets divided into two. There appears to be two cities living within one big city - Old Gurgaon and New Gurgaon. Old Gurgaon has poor infrastructure, insufficient facilities and is congested whereas New Gurgaon is well planned and fast developing with high-rise residential apartments, shining malls and huge and widespread offices of almost all the big Multi-National Companies. DLF (Delhi Land and Finance) has played a crucial role in the high pace development of Gurgaon. The area that I would be referring to is DLF Phase V in Gurgaon which is one of the many residential areas developed by the DLF as part of their project of constructing DLF City or the New City in Gurgaon. All the information presented in this section is based on the interviews that were conducted by me.

DLF Phase $\mathrm{V}$ comprises of numerous high rise residential apartments of 15-20 floors. These apartments are gated and are equipped with strong security systems with guards placed at various entrances, intercoms, CCTV cameras, two security checks which might involve frisking and questioning about one's identity and purpose of visit. However this is not enough. One can get entry only after a telephonic confirmation by the person whom one wants to visit. A proper 
record is maintained of the cars that come in and the visitors who walk in. Nonetheless, what catches attention in these high rise residential apartments and their strong security system is the increasing presence of private security agencies. This process of privatization can be seen as a direct impact of neoliberal policies.

The security provided in most of these gated complexes is through private security agencies. The nature of employment in these security agencies has kept balance with the neo liberal policies of informalization and flexibility of labour. The guards employed are not organized under any union and all of them are employed on contractual basis. Let us not forget the abundant supply of unemployed labour in India. It also came across through the interviews that the guards employed were made to work over their eight hour shift in most of the cases without any money paid for the extra work they were putting in. In a few cases guards were also under aged. Thus, we see that this urban development has managed to all possible labour laws. However the acute shortage of employment opportunities and the desperate need of money to sustain their families leave these young men with no other option but to provide their services to this kind of exploitation without much resistance.

In terms of keeping tight security there is one more activity which catches one's attention. It somehow appeared more as a ritual showcasing DLF's exclusivity or a sign of pride to me. Every morning and evening two horses and two sniffer dogs with an escort are seen to be taking a walk on the main road which has high rise gated complexes on both sides of the road. They are on the road for a good 45 minutes to an hour. This 'ritual' gives the residents a sense of pride as most of them say that 'it is for the first time that they see this happening that too in their locality' which again marks them as being different and superior to others. Thus we see that there is not only exploitation of a particular class, but it also creates a divide among the people of the same class too.

One of the consequences of the division of society and of gated living is the criminalization of the other - meaning anyone who does not belong to a class which is capable affording these apartments is seen with suspicion as being a threat to the security of the residents. There is thus a constant targeting of the working class of men and women who work as nannies, cooks, house helps and drivers. Despite being a daily visitor to the complex every time they enter they are asked to show their identity cards and without the identity cards it is difficult for them to make it inside the compound. There is an assumption that the sections of people who form the working class are generally the ones who are the trouble makers. Thus, there needs to be a constant scrutiny of this section of the people. This kind of security is not enough to satisfy the residents. None of the local vendors, hawkers, waste pickers, redi walas selling vegetables, fruits etc. get permission to enter the gates of these high rises to avoid confusion, chaos and noise. Redi walas refers to the road side vendors in India. They vary from those who occupy a part of the foot path, most of the time without a rooftop to display the items that they are selling, to once who are much more mobile and one neighbourhood to another to sell the items that they have. They are perceived as being an unnecessary nuisance that hinders the planned and 
systematic lifestyle and a threat to the safe and secure living of the people inside the gated community.

Most of these gated complexes do not have a Residential Welfare Association to take care of the grievances of the residents. Instead of the Residential Welfare Association, Condominium Association is what functions in the gated high rises. What came across in one of the interviews was that the Condominium Association does not have even one resident as representative. The members of the Condominium Association are the ones nominated by the DLF. By having Condominium Associations DLF leaves no space for the residents to indulge in any activity against itself so that the smooth implementation and functioning of DLF is ensured. Thus, we see that the neoliberal policy driven world has little space for democracy and dissent.

Even when security and exclusivity are the dominant reasons for the promotion of a gated lifestyle, there is a difference in what we see in the Indian context. On, the one hand, we see exclusivity in relation to the other fellow citizens of India. Though, there is a disconnection at the local level, there seems to be a connection at the global level. What one sees happening today is the alienation of people, but with greater complexities and modifications. So, what seems to be happening is the alienation of a section of a people from the rest of the society. An individual forms its identity from the society of which it is a part. With the capitalist intention of alienation at work, every individual is being robbed of its individuality being reduced to an isolated and unencumbered individual. But, what makes the present system more complex is the fact that gated residential complexes seem to be providing a resemblance or an inclusion of Western lifestyle. This influence of Western ways of living is not only apparent from the structure of the high rises but also through their names. Instead of having Indian names of the complexes they have western names like Carlton Estate, Wellington Estate, Princeton, Trinity, Westend Heights to name a few. This style of naming gives a sense of being western and thus superior to the others in the city and also a sense of exclusivity. The immense stress that is given on the promotion of exclusivity and the idea of being Western is also evident if we look at the real-estate advertisements for gated living. Most of the advertisements of gated complexes discuss exclusive facilities alongside an emphasis on the world class amenities and specification that are at par with the international standards and ways of living. Thus, where there is disconnect from the more proximate community there seems to be a connection with a distant community.

Here, I would like to share a few newspaper advertisements that I came across in one of the famous daily newspapers of India. It becomes evident from these that the builders play on the importance of the Western lifestyle and exclusive ways of living. One of the advertisements said - "The irresistible lifestyle. Nestled within the tranquil environs of inimitable neighbourhoods, they are conceived for those who seek the distinguished standards of style, comfort, recreation and innovation." Yet another goes like this - "Now the future isn't another time. It's another place. Citynext. Your destination for an enhanced lifestyle. Where home is where the lifestyle is-an avant-garde colonies with their 
own clubs, swimming pools, sports facilities and thorough gated security, where leisurely drives down beautifully landscaped expressways replace the customary traffic jams. If the outdated chowkidar [chowkidar is a Hindi word for a Gate Keeper whose responsibility is to guard the entrance and thus ensure safety] is your idea of safety, you're living dangerously. If immaculate Gated complexes and world class Golf Courses are your dream, consider them fulfilled." However it seems that this kind of lifestyle is only for a select few as one of the advertisement said - "Destination for the privileged few." These advertisements are actually fuelling the creation of neoliberal subjects in definitely other ways that what was discussed in the initial part of the paper. What these advertisements do is that they play with the aspirations and desires of the people. These advertisements driven by the capitalist market intentions create new aspirations and desires depending on what they produce. This results in people engaging in excessive and mindless consumerism which serves the capitalist purpose.

\section{Conclusion}

Thus, to conclude from the discussion above we can say that the exclusivity, security and representation of one's status forms the basis on which gated complexes are selling in the Indian context. However, it becomes important for us to critically analyze the idea of exclusivity as well as securitization and what they imply in the Indian context. The question that then needs to be raised is - is it legitimate on the part of the government and authorities to provide exclusive living for a few by compromising on the basic amenities to be provided to the poor? What will be the consequences and manifestations of this kind of urban development which has led to the appropriation of public land for private use which is completely in tune with the neoliberal principles of privatization? On the other hand, in relation to the process of securitization the question that we need to raise is- how far is this security for a few based on constant criminalization and exploitation of the other justified? This process of securitization creates new subjects. These subjects created through the process of securitization are constantly subjected to the fear of crime which is crafted and created rather than it being real and existent. This is entirely guided by the capitalist intentions which do not only aim at producing goods, but also aim at producing consumers for the products and thus creating a market. In the age of technological advancement our situation as subjects has become even more vulnerable because it makes it absolutely impossible for the subjects to escape her/his subjectivity while it makes the logic of the market to be reinforced and imposed on us with utter ease.

\section{References}

[1] Romi Khosla, 'The City as an Idea' in Romi Khosla (ed), The Idea of Delhi (Mumbai: Marg Publications, 2005) 10.

[2] Janaki Nair, The promise of the Metropolis: Bangalore's $20^{\text {th }}$ century (New Delhi: Oxford University Press, 2005) 4. 
[3] David Harvey, Consciousness and the Urban Experience (UK: Basic Blackwell, 1985) 250, 251.

[4] Sujata Patel and Kushal Deb, Urban Studies (New Delhi: Oxford University Press, 2006) 5.

[5] Henri Lefebvre, The Production of Space. (Oxford: Blackwell Publishers, 1991).

[6] Mark-Anthony Falzon, 'Paragons of Lifestyles: Gated Communities and the Politics of Space in Bombay', City and society, vol. 16, issue 2.

[7] Sameer Bagaeen, 'Gated Communities: Social Sustainability in Contemporary and Historical Gated Developments' 1. Available at: www.economicgeography.org

[8] Sonia Hirt and Mina Petrovic, 'The Belgrade Wall: The Proliferation of Gated Housing in the Serbian Capital after Socialism', International Journal of Urban and Regional Research, vol. 35.4, July 2011, 755.

[9] Edward J Blakely and Mary Gail Snyder, Fortress America: Gated communities in United States (Booking Institute Press, 1999).

[10] Basak Tanulku, 'Gated Communities: From Self-Sufficient Towns to Active Urban Agents', Geoforum 43, 2012, 518.

[11] Setha Low, Behind the Gates: Life, Security, and the pursuit of Happiness in Fortress America (New York: Routledge, 2003).

[12] Bruce Epperson, 'Is Form Destiny? Technologies of Personal Security', Project Muse, Technology and Culture, vol. 45, no. 3, July 2004, 2.

[13] Axel Borsdorf, Rodrigo Hidalgo, Rahael Sanchez, 'The new model of Urban Development in Latin America: The Gated Communities and Fenced Communities in the Metropolitan Cities of Santiago de Chile and Valparaiso', Cities, vol. 24, no. 5, 2005, 366.

[14] Robert W. Helsley, William C. Strange 'Gated Communities and the Economic Geography of Crime', Journal of Urban Economics, 46(1), 1999, 102.

[15] Rowland Atkinson, Sarah Blandy, et al., "Gated Cities of Today? Barricaded Residential Development in England", The Town Planning Review, vol. 76, no. 4, 2005, 410.

[16] Jill Grant, 'The Function of Gates: The Social Construction of Security in Gated Developments', The Town Planning Review, vol. 76, no. 3, 2005, 301.

[17] Georgeanna Wilson-Deonges, 'An Exploration of a Sense of Community and Fear of Crime in Gated Communities', Environment and Behavior, vol. 32, no. 5, September 2000, 599, 600.

[18] Don Mitchell, The Right to the City: Social Justice and the Fight for Public Space (New York: The Guilford Press, 2003) 13.

[19] Aron Gooblar, 'Outside the Walls: Urban Gated Communities and their Regulation within the British Planning System', European Planning Studies, vol. 10, no. 3, 2002, 321, 324. 